\title{
INFLUENCE OF THE WELDING PROCESS ON CHANGES IN THE S460MC FINE-GRAINED STEEL JOINTS FATIGUE LIFE
}

\author{
1'Jaromir MORAVEC, ' Jan NOVÁK, ' Jiri SOBOTKA, 'IVa NOVÁKOVÁ \\ ${ }^{1}$ Technical University of Liberec, Liberec, Czech Republic, EU, jaromir.moravec@tul.cz, jan.novak@tul.cz, \\ iiri.sobotka@tul.cz,iva.novakova@tul.cz
}

https://doi.org/10.37904/metal.2020.3501

\begin{abstract}
Structural designs of the dynamically loaded welded structures are currently based primarily on the values of the parent base material fatigue life. Although it tries to capture the influence of the given process by using the safety constants of the notch effect both of the weld and the thermal influence, it is only a theoretical estimation. Due to that, it very often results in large oversizing and, in worse cases, in under-sizing of the engineering design. As a result, there is either an overly robust and heavy construction, which is unacceptable (especially when applied in the automotive industry) or on the contrary, there is failure of parts due to cracks earlier than their planned service life is reached. The paper shows the effect of MAG welding method on the fatigue life of fillet and butt welds made of the fine-grained structural steel S460MC. The comparison of such influence is performed via using experimentally determined Wöhler curves of the parent material and both types of welded joints.
\end{abstract}

Keywords: Welding, Fatigue Life, Fine-grained Steels, S-N Curves, S460MC Steel

\section{INTRODUCTION}

In recent years, the number of metal structures that are during their service life exposed to cyclic loads due to the nature of their operation or external conditions has been growing. Such constructions occur in most branches of human activity, but increased attention is paid to them especially in the automotive industry. [1] However, the design proposals and numerical calculations of dynamically loaded parts are usually based on the values of parent material fatigue life, reduced by safety constants including the shape complexity and size of the part, even. the notch effect. However, it is still only a theoretical estimation, because the fatigue curves (Wöhler curves) of welded joints for specific materials are usually not available. Very often, it leads to a significant oversizing and, in worse cases, to an under-sizing of the engineering design. The result is either an overly robust and heavy construction, which is unacceptable (especially when applied in the automotive industry) or on the contrary, the parts crack even before their planned service life is reached $[1,2]$. That is why the fatigue curves of real welded joints make possible to significantly specify design proposals as well as the numerical shape and strength optimization. Thanks to this, it is possible to specify not only the existing safety constants used in the computation, but also to include in the design the influence of material changes caused by the thermal cycle, weld geometry and resulting deformation.

Already from the initial effect of cyclic loading, irreversible material changes occur at the microscopic level in the loaded part, which are termed as fatigue of material. These changes are caused by the stress, which will not cause any problems right under static loading. Usually, such stress is lower than the yield strength of used material. Repeated variable loads lead to the accumulation of local damage, causing the formation of surface and subsurface cracks, their propagation and (as a result) the fatigue fracture. In the theory of fatigue fractures, the material is not considered to be a homogeneous medium and therefore does not follow the laws of continuum mechanics [3]. 


\section{EXPERIMENT OBJECTIVES AND USED MATERIALS}

The goal of the experimental part was to find out how intensely the welding process can affect the fatigue properties of a joint made of fine-grained, structural, thermos-mechanically processed steel S460MC. It is a steel that is currently very often used both for statically and dynamically loaded structures. As examples there are truss structures of bridges, cranes, axle parts of cars and trucks, etc. It is a ferritic-pearlitic (Figure 1) steel having good weldability, low content of carbon, as well as elements such as $S$ and $P$. Chemical composition of the material determined by the Q4 TASMAN spectrometer is shown in Table 1. The determined chemical composition is in accordance with the standard ČSN EN 10149-2 indicating the chemical composition of structural thermos-mechanically processed steels [4].

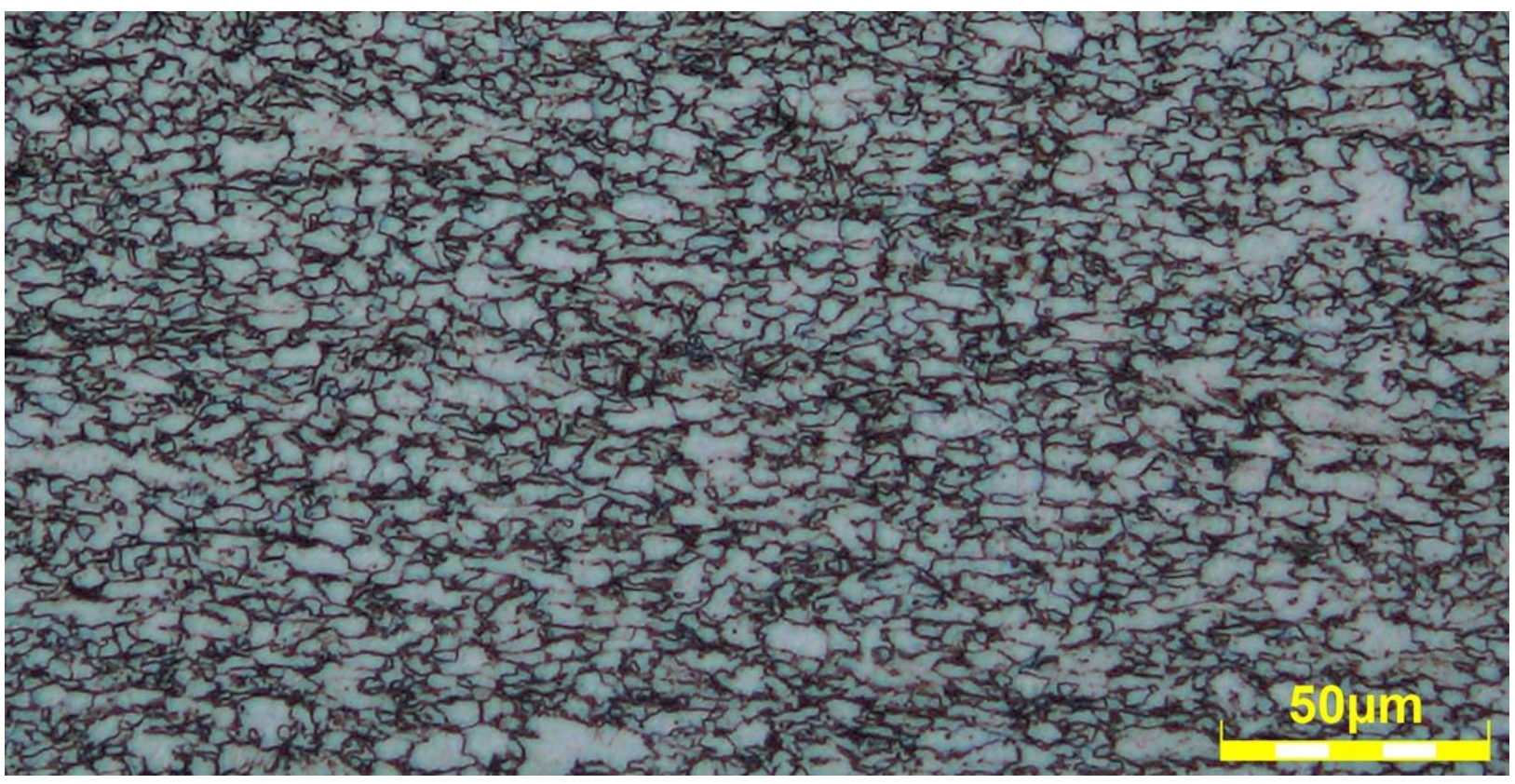

Figure 1 Structure of the basic material S460MC

Table 1 Chemical composition of material S460MC

\begin{tabular}{|c|c|c|c|c|c|c|c|c|c|c|c|}
\hline $\begin{array}{c}\text { Chemical } \\
\text { elements }\end{array}$ & $\mathbf{C}$ & $\mathbf{M n}$ & $\mathbf{S i}$ & $\mathbf{P}$ & $\mathbf{S}$ & $\mathbf{N b}$ & $\mathbf{W}$ & $\mathbf{N i}$ & $\mathbf{V}$ & $\mathbf{C r}$ & $\mathbf{T i}$ \\
\hline $\begin{array}{c}\text { Composition } \\
\text { [wt\%] }\end{array}$ & 0.07 & 1.32 & 0.01 & 0.03 & 0.01 & 0.05 & 0.04 & 0.04 & 0.08 & 0.01 & 0.01 \\
\hline
\end{tabular}

Subsequently, the mean grain size of $7.3 \mu \mathrm{m}$ was determined by the EBSD analysis. This is the average value obtained from three measurements of areas $0.6 \times 0.6 \mathrm{~mm}$ [4]. To assess the mechanical properties under static and dynamic loading, a static tensile test was performed at first and then was determined the Wöhler curve of the base material. Table 2 shows the mechanical properties determined from the static tensile test and taken as the average of five measurements.

Table 2 Mechanical properties of material S460MC (measured from static tensile test)

\begin{tabular}{|l|c|c|c|c|}
\hline & $\begin{array}{c}\text { Upper Yield Strength } \\
\mathbf{R e}_{H}[\mathrm{MPa}]\end{array}$ & $\begin{array}{c}\text { Ultimate Strength } \\
\mathbf{R m}[\mathbf{M P a}]\end{array}$ & $\begin{array}{c}\text { Uniform Ductility } \\
\mathbf{A g}[\%]\end{array}$ & $\begin{array}{c}\text { Total Ductility } \\
\mathbf{A}_{\mathbf{3 0}}[\%]\end{array}$ \\
\hline ČSN EN 10149-2 & $\min .460$ & $520-670$ & - & min. 17 \\
\hline Measured values & 544 & 629 & 13.15 & 29.03 \\
\hline
\end{tabular}


All cyclic tests of the parent material were performed in the controlled force mode on the servo-hydraulic tester INOVA FU-O-1600-V2 with a maximum achievable force load of $100 \mathrm{kN}$. For the experiments samples of circular cross-section in accordance with the standard ČSN EN 3987 were used (see Figure 2). The samples were tested under selected stress levels by fully reversed cyclic loading with stress ratio $R=-1$ and frequency $40 \mathrm{~Hz}$. The stress amplitude was kept constant for each stress level. As a criterion to terminate test was taken fracture failure of the sample, or exceeding the limit of $10^{7}$ cycles. A total of 21 samples were tested (Figure 2) at stress levels as following 450; 400; 375; 350; 343; 337.5; 325 and $312.5 \mathrm{MPa}$. Based on the achieved results was determined the fatigue strength of the parent material as $\sigma \mathrm{c}=340 \mathrm{MPa}$.

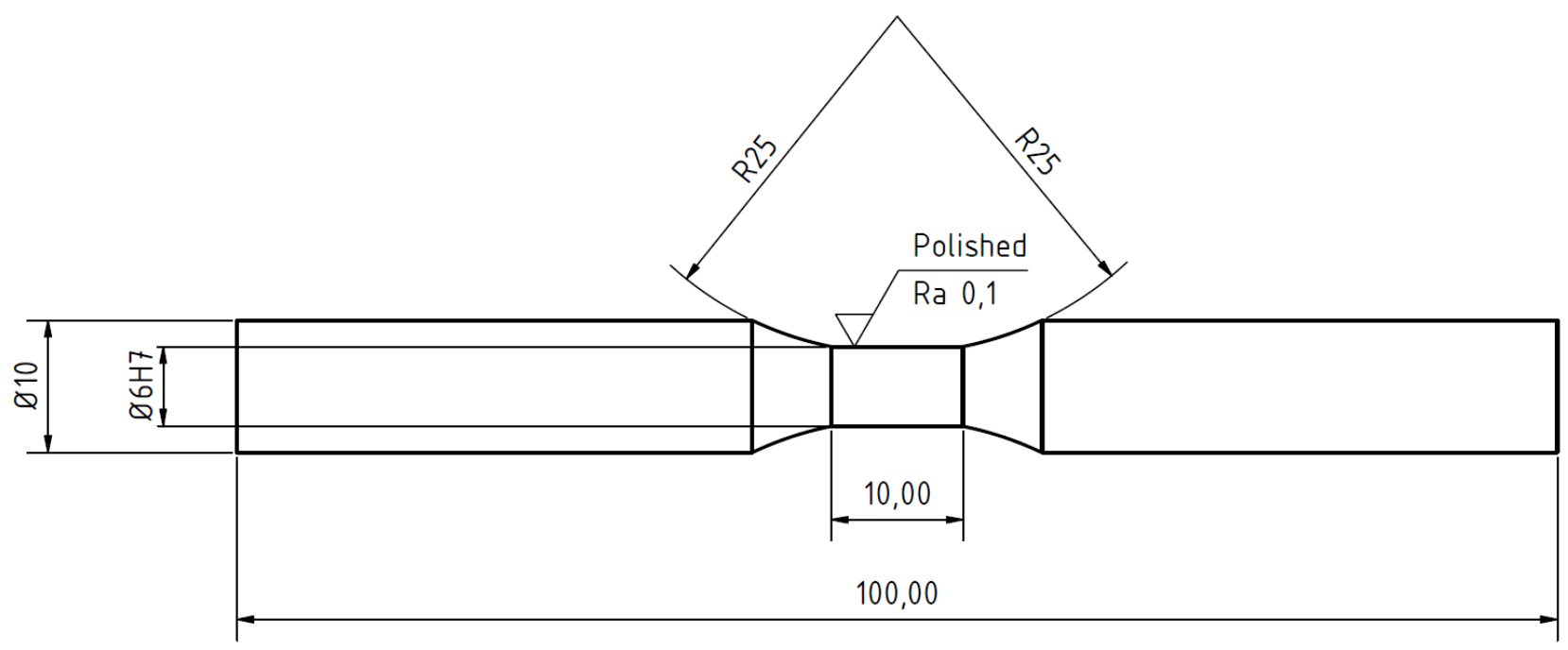

Figure 2 Testing samples for the high-cycle fatigue test

\section{WELDING OF TESTING SAMPLES}

Firstly, the double-sided fillet weld was made. It was done from semi-finished products as $250 \times 190 \times 10 \mathrm{~mm}$ for the flange and $250 \times 110 \times 10 \mathrm{~mm}$ for the web. The web was milled in the area of contact with the flange so that the contact between web and flange was uniform along the entire length. There was used MAG welding method, with the torch mounted in a linear automat and the sample placed in the jig in the PA position, whereas the angle between torch and flange was $30^{\circ}$. The additional material OK Autrod 12.51 with a diameter of 1.2 $\mathrm{mm}$ and shielding gas M21 according to ISO 14175 with a flow rate of $15 \mathrm{I} \cdot \mathrm{min}^{-1}$ was used. Welding parameters were monitored by the WeldMonitor system. The measured welding current was $325 \mathrm{~A}$, voltage $29.8 \mathrm{~V}$ and travel speed $0.502 \mathrm{~m} \cdot \mathrm{min}^{-1}$. After welding were measured deformation of flange and web along the entire length of weld. Angular deformation after first pass was $1.82 \mathrm{~mm}$ in the case of flange and $2.21 \mathrm{~mm}$ for web. After the second pass, angular deformation of the web decreased by $0.53 \mathrm{~mm}$ and the angular deformation of the flange increased to $4.35 \mathrm{~mm}[6]$.

The butt weld was made as a three-layer $V$-weld from semi-finished products and having dimensions as following: $250 \times 80 \times 10 \mathrm{~mm}$. It was welded in the PA position with excess weld metal height $1.5 \mathrm{~mm}$, included angle $60^{\circ}$ and root gap $1.1 \mathrm{~mm}$. The first pass was welded at current $215 \mathrm{~A}$, voltage $20.2 \mathrm{~V}$ and travel speed $0.501 \mathrm{~m} \cdot \mathrm{min}^{-1}$, the second pass was welded at current $266 \mathrm{~A}$, voltage $25.3 \mathrm{~V}$ and travel speed $0.503 \mathrm{~m} \cdot \mathrm{min}^{-1}$ and finally the third pass was welded at current $293 \mathrm{~A}$, voltage $27.9 \mathrm{~V}$ and travel speed as $0.501 \mathrm{~m} \cdot \mathrm{min}^{-1}$. Angular deformation was measured just after welding of all passes and was $5.92 \mathrm{~mm}$. The following Figures $\mathbf{3} \mathbf{a}$ and $\mathbf{3} \mathbf{b}$ show scratch patterns of fillet ( 3 on the left) and butt ( 3 on the right) welds - including basic dimensional analysis [7]. 

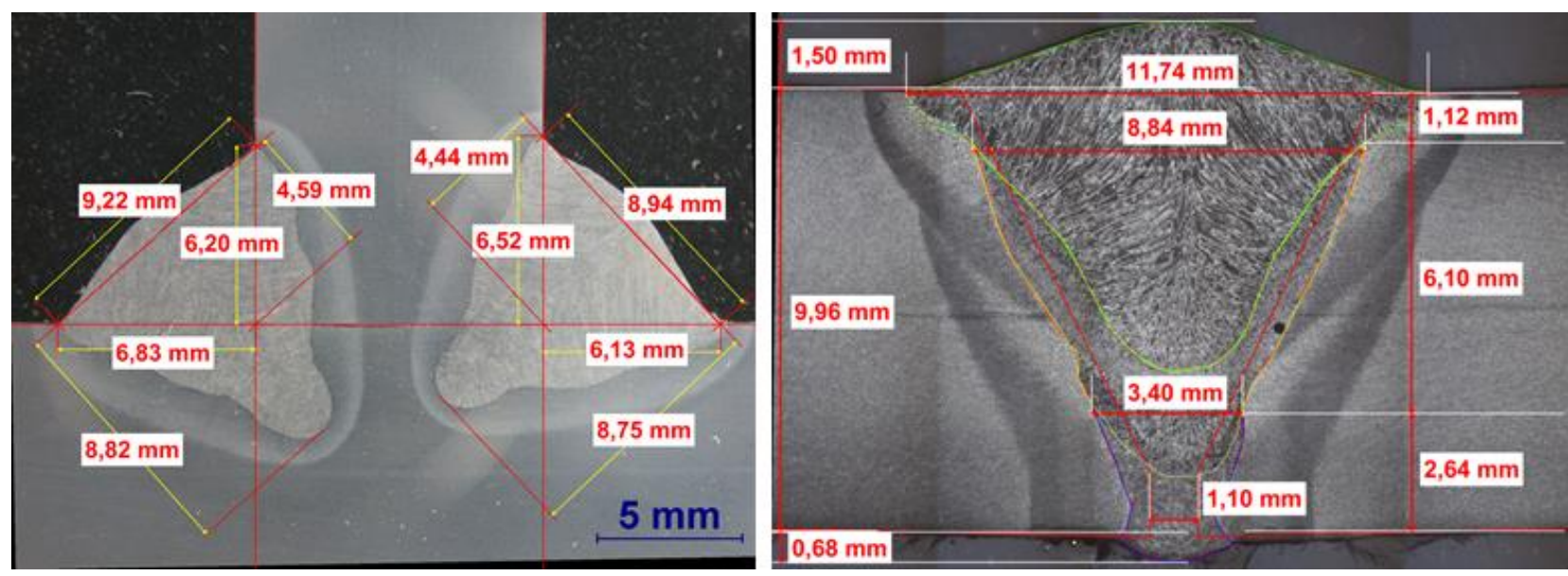

Figure 3 Metallographic scratch patterns of fillet (left) and butt (right) weld with the basic dimensional analysis

Both filet and butt welds were totally made as three pieces so that a sufficient number of samples was available for the subsequent fatigue life tests. The welds were cut by a band saw having $20 \mathrm{~mm}$ width, while the initial and final $40 \mathrm{~mm}$ of weld was not used. As a reason there was effort to use only samples from the region of a stable temperature field, where constant geometry and weld properties can be expected. After cutting, flanks of the weld were milled and subsequently re-grinded so that any notching effect after cutting the material was completely eliminated.

\section{FATIGUE TESTS OF WELDED JOINTS}

As in the case of parent material fatigue tests, the servo-hydraulic tester INOVA FU-O-1600-V2 was used and again in the mode of controlled force at fully reversed cyclic loading with stress ratio $R=-1$. Due to the different shape of the sample, the higher cross-section values and thus also the loading forces, a lower frequency of $20 \mathrm{~Hz}$ had to be used. The specimens were loaded as it is shown in schematic Figure 4. However, due to deformation after welding, in this case it was a combined tensile-compressive-bending stress.

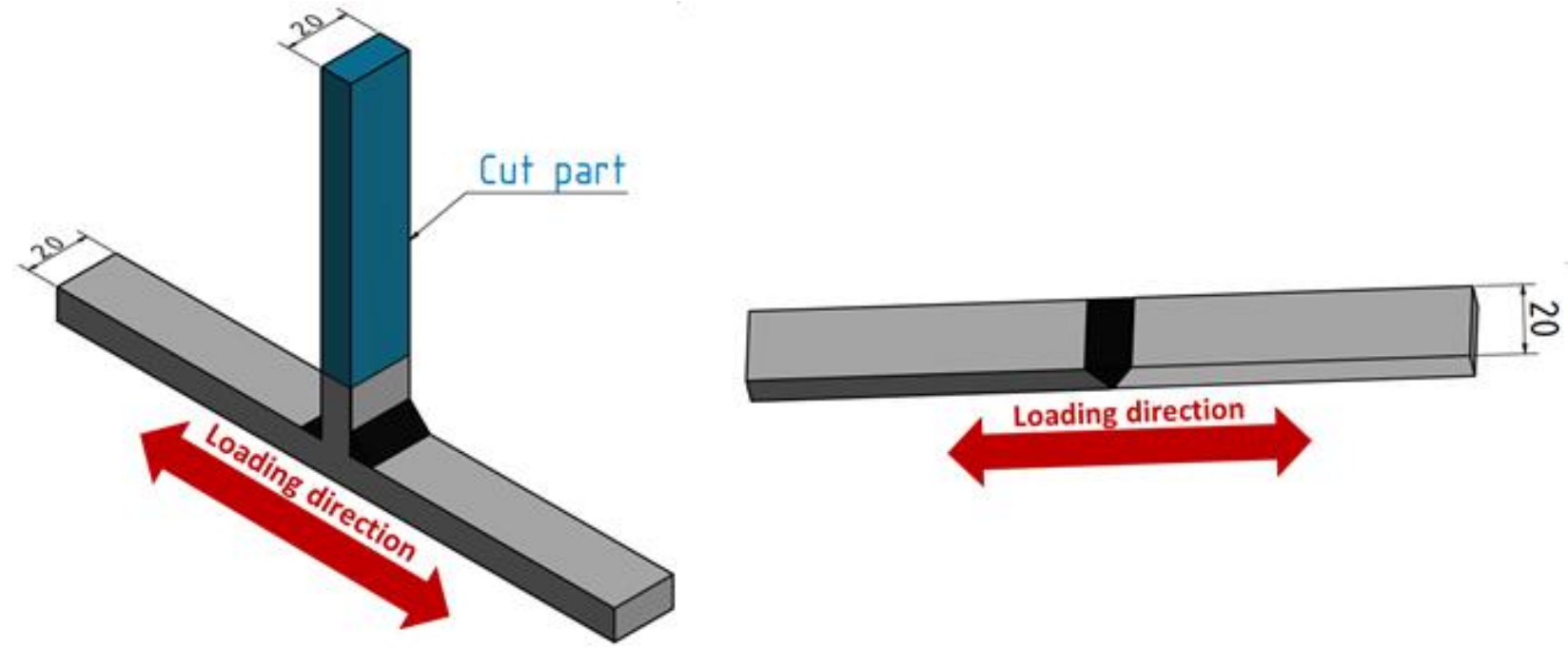

Figure 4 Stress of samples at cyclic loading

For fillet welds, a total of 15 specimens were loaded at stress amplitude $\sigma_{A}$ in the following levels: 300; 240; $170 ; 152.5 ; 135 ; 117.5 ; 100 ; 90 ; 85 ; 75$ and $65 \mathrm{MPa}$. For butt welds, again a total of 15 samples were loaded 
at stress amplitude $\sigma_{\mathrm{A}}$ in the following levels: $300 ; 287.5 ; 275 ; 262.5 ; 250 ; 237.5 ; 225 ; 212.5 ; 200 ; 188$ and $175 \mathrm{MPa}$. Determined Wöhler curves for the parent material and both types of welded joints are shown in Figure 5. The fatigue strength $\sigma_{c}=188 \mathrm{MPa}$ was determined for butt welds and fatigue strength $\sigma_{\mathrm{c}}=65 \mathrm{MPa}$ was determined for fillet welds.

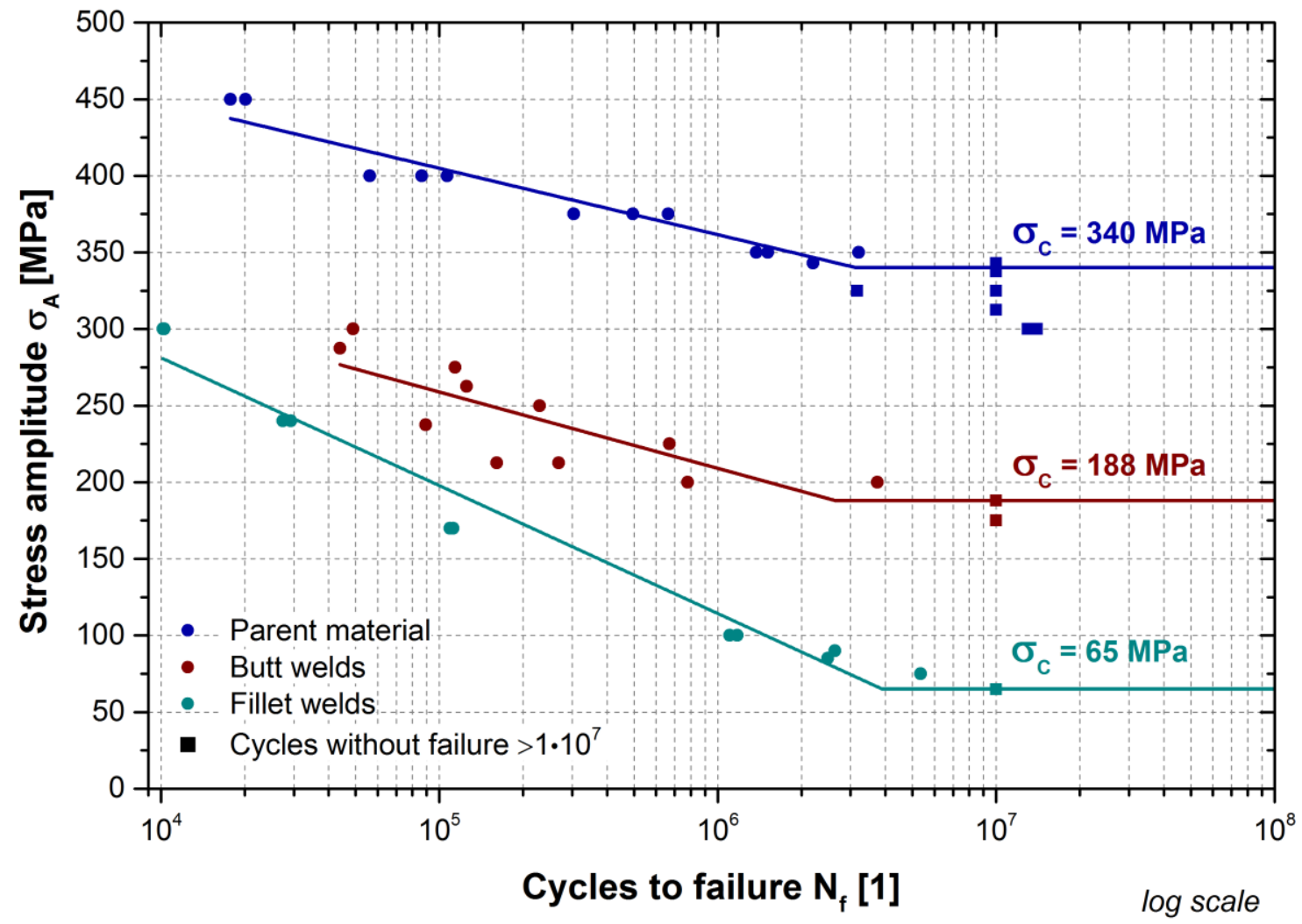

Figure 5 Wöhler curves for the parent material and both types of welded joints

\section{DISCUSSION AND CONCLUSION}

From the courses of Wöhler curves for parent and both types of welds is evident that several factors have an effect on the change of material fatigue life. One of them is the heat introduced into the parent material and causing structural changes in the heat affected zone (HAZ). Another consequence of the introduced heat and non-stationary temperature fields is creation of stresses resulting in deformation of material. In the case of lowcarbon steels, the structural changes in HAZ are very small and hardly affect the mechanical properties of the material, as demonstrated by HV10 hardness measurements. The difference in hardness values between the parent material, weld and HAZ was lower than $17 \mathrm{HV}$ for both types of welds.

On the other hand, deformation of the material after welding already has a certain effect, because it adds bending stress to the uniaxial tensile/compressive stress, by which were tested all samples. Due to that, it reduces the fatigue life of tested material. Although the angular deformations were greater in butt welds than in fillet welds, a higher fatigue strength $\sigma_{c}$ was achieved in the case of butt welds. Based on the additional experiments with welded specimens, where the angular deformations were removed by milling, the effect of bending stress caused by weld angular deformation was quantified in the range of $12-18 \%$.

Another, and in the case of welds very crucial factor that affects the magnitude of material lifetime is the notch effect of the weld. This effect is especially evident in fillet welds, where (due to the design principle) the notch is much larger than in butt welds. For all tested welds (both butt and fillet), the fatigue fracture was initialized 
and propagated right in the area of the largest notch, i.e. at the location of the highest stress concentration, and the fracture subsequently propagated perpendicular to the loading direction of sample.

The highest value of the fatigue strength has the parent material, where was experimentally determined the fatigue strength of $\sigma_{c}=340 \mathrm{MPa}$. It is generally stated that the fatigue strength of the parent material corresponds approx. to $40 \%$ of its ultimate strength. In the case of fine-grained S460MC steel, the fatigue strength corresponds to approx. $54 \%$ of the ultimate strength for this material. In both types of welds, it has been shown that the notch effect has the greatest influence regarding the fatigue life of tested material. For this reason, the fatigue strength of samples welded by butt welds was almost three times higher than that of samples welded by fillet welds. Even so, the fatigue strength of butt welds decreased by $45 \%$ compared to the parent material and even by $80 \%$ in the case of fillet welds.

\section{ACKNOWLEDGEMENTS}

This work was supported by the Student Grant Competition of the Technical University of Liberec under the project No. SGS-2019-5015 "Research and development for innovation of materials and production technologies with application potential in mechanical engineering".

\section{REFERENCES}

[1] GODEFROID, L.B., et al. Fatigue failure of a welded automotive component. Procedia materials science. 2014, vol. 3, pp. 1902-1907. Available from: https://doi.org/10.1016/i.mspro.2014.06.307

[2] CHETAN, J. S., KHUSHBU, P.C., FAJALHUSEN, P. A review of the fatigue analysis of an automobile frames. International Journal of Advanced Computer Research, 2012, Vol. 2, No. 4, pp. 103-107.

[3] ZAPLETAL, J., VĚCHET, S. Nizkocyklové a vysokocyklové únavové vlastnosti ADI. Brno: Vysoké učení technické v Brně, Fakulta strojního inženýrství, 2011.

[4] ŠEBESTOVÁ, H. et al. Fatigue properties of laser and hybrid laser-TIG welds of thermo-mechanically rolled steels. Materials Science and Engineering. 2020, vol. 772A, 138780. Available from:

https://doi.org/10.1016/j.msea.2019.138780

[5] LEONETTI, D., MALJAARS, J., SNIJDER, H., Bert, H. Fitting fatigue test data with a novel SN curve using frequentist and Bayesian inference. International Journal of Fatigue, 2017, vol. 105, pp. $128-143$.

[6] MORAVEC, J. et al. Determination of Grain Growth Kinetics and Assessment of Welding Effect on Properties of S700MC Steel in the HAZ of Welded Joints. Metals. 2019, vol. 9, no. 6, pp. 707-714.

MIČIAN, M. et al. Effect of the T8/5 cooling time on the properties of s $960 \mathrm{mc}$ steel in the HAZ of welded joints evaluated by thermal physical simulation. Metals. 2020, vol. 10, no. 2, pp. 229-235. 